\title{
10 Practical Uses of the Method of Epigenetic Regulation of Protein Synthesis in the Agricultural Field
}

\author{
Victor Prévost, Michel Duhamel and Pedro Ferrandiz \\ Genodics SAS \\ Joël Sternheimer \\ Université Européenne de la Recherche
}

\section{CONTENTS}

Introduction: The Genodic Method. 111

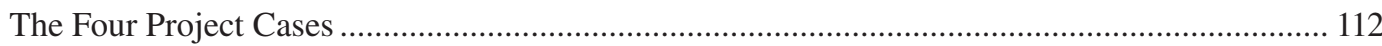

Materials and Methods for the Four Cases ….......................................................................... 112

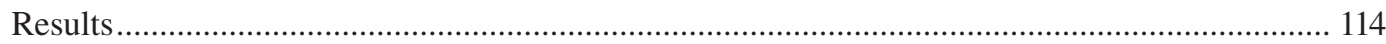

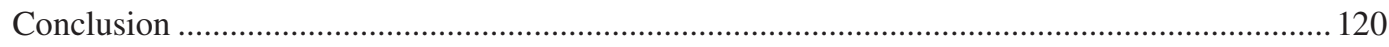

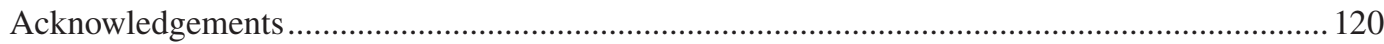

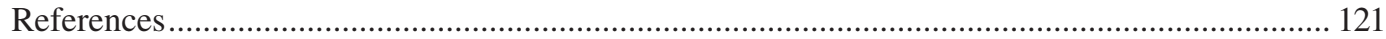

\section{INTRODUCTION: THE GENODIC METHOD}

Genodics is a discipline introduced by the physicist Joël Sternheimer that aims to describe interactions of an undulatory, wave-like nature (de Broglie waves; de Broglie, 1924) that are involved in the regulation of the biosynthesis of macromolecules associated with gene expression. The application of this discipline has resulted in a method for the epigenetic regulation of the biosynthesis of specific proteins in living organisms, by means of sound diffusions called proteodies, which reproduce certain characteristics of the targeted proteins through a succession of audible frequencies forming a structured melody. The process was discovered and patented by Sternheimer based on his work in theoretical physics that subsequently found applications in biology (Sternheimer, 1992).

All proteins are chains of molecules called amino acids, in a specific order. To transpose them into modulated sound waves or protein melodies (proteodies), each amino acid is allocated a sound wave frequency calculated with the matter-wave equation of de Broglie and transposed into the audible range according to the rules of harmonics. The resulting series of sound are interpreted by choosing a type of voice and a tempo and modulating the duration of each note, in order to get an actual musical score. On small samples, such as in a laboratory, the broadcast equipment can be a simple mp3 reader, combined with a time programmer. In greenhouses or outside, bigger broadcast devices are used that are autonomous (with solar panel and battery), water-resistant and programmable via Global System for Mobile Communications (GSM). More powerful than small mp3 readers, with 4 loudspeakers and 2 amplifiers, each proteody box or P-Box can cover up to 15 ha. Broadcasted programmes are short, from 5 to 10 minutes, but can be repeated from 1 to 5 times daily, according to the needs of plants. Each broadcast programme includes several relevant 
proteodies and corresponds to a specific metabolism to regulate or to a plant disease to reduce. On polycultures, the broadcast programmes are modified more often than on monocultures, in order to respond day after day to the needs of each type of plant, as observed by the farmer.

Genodics is also the name of a biotechnology company, created to develop applications for this process and to provide market proof of the concept. To date, the company has established 280 treatment installations, spread over 2,500 ha of crops (vines, market gardening and arboriculture) and 180 farms. The company's activities address many different agricultural issues.

\section{THE FOUR PROJECT CASES}

In this chapter, we present four projects conducted by Genodics, the results of which show a significant number of effects that hold potential for the expansion of the process and the development of new applications. The projects are outlined below.

Case $1 a, b$ and $c$ : The prevention and reduction of the effects of Esca on vines between 2008 and 2019. Esca is a cryptogamic (spore-based), vascular wilt disease involving a large number of anaerobic fungi, which develop inside the woody parts of the vine and can lead to the sudden death of the vine stock by blocking the rise of sap (apoplexy). This project was carried out throughout France following the ban on the use of sodium arsenite in 2002 (Ferrandiz et al., 2018; Bargoin et al., 2004).

Case 2: The prevention and reduction of the impact of Grape Powdery Mildew on a 7-ha vineyard. This mildew is caused by the fungus Plasmopara viticola. It affects the leaves and berries and can substantially weaken the vigour of the vines, as well as the volume of the harvest and the quality of the wine.

Case 3: The prevention and reduction of the impact of Erwinia on endives. Erwinia is a bacterial disease causing brown rot in endive, which has a strong impact on their quality and the marketable quantity.

Case 4: The reduction of the impact of mosaic viruses on courgettes. Zucchini Yellow Mosaic Virus (ZYMV) and Watermelon Mosaic Virus (WMV2) affect cucurbit crops. These viruses can cause extremely severe damage, resulting in significant crop losses.

The data used in this study come directly from the farms using the genodic process. The data were collected either by the farmer and his/her teams or by the Genodics team with verification and validation by the farmer. All measurements were based on the actual production of the farms under normal conditions, and therefore reflect the actual impact, in real terms, of the use of the process.

In general, the acoustic sequences produced from the protein structures of the plants concerned aim to stimulate their defence metabolisms, and those corresponding to pathogens aim to reduce their activities. The process thus tends to inhibit the pathogen and limit its impact on the host (Sternheimer, 2006).

\section{MATERIALS AND METHODS FOR THE FOUR CASES}

In the cases presented, the following evaluation methods were used, as shown in Table 10.1.

These cases are representative of the spectrum of action of the process on different kingdoms of living organisms, whether vegetal (vine, endive, courgette), bacterial (Erwinia), fungal (Esca and Mildew) or viral (Mosaics).

The installation of the acoustic diffusion system required is adapted to the agricultural context and the evaluation method chosen. In general, a stand-alone sequence diffusion box is installed to cover a maximum surface area, with additional diffusion boxes on larger surfaces. In order to highlight a diffusion gradient (in the cases of Grape Powdery Mildew and courgette Mosaic), part of the production is deliberately left out of reach of the diffuser in order to be able to compare the 
TABLE 10.1

\section{Evaluation Methods Used for Each of the Four Cases}

$\begin{aligned} & \text { Case } \\ & \text { All cases (general) }\end{aligned}$
$\begin{aligned} & \text { Counting (exhaustive or statistically significant sampling) of symptoms and mortality related to the } \\ & \text { presence of a pathogen in the study population } \\ & \text { Comparison with historical data from the same plots } \\ & \text { control }\end{aligned}$
$\begin{aligned} & \text { Esca with control } \\ & \text { Mildew and Mosaic } \\ & \text { viruses }\end{aligned}$
$\begin{aligned} & \text { Comparison with data from a control group with the same characteristics and growing conditions } \\ & \text { the power of the sound (the acoustic scattering mode) }\end{aligned}$

development of the crop as well as the presence of the fungus or viruses at different distances from the diffusion device.

Case $1 a$ and $b$ : Prevention and reduction of the effects of Esca on vines.

A count of vines showing symptoms of Esca was carried out each year over 1-6years around the harvest period on 91 plots of productive vineyards in France, covering a total of 260 ha, and compared with counts undertaken on the same plots during 1-3 years before the broadcast of sequences, in order to accurately estimate the pressure linked to the presence of the pathogen on the plots as well as the mortality associated with it. Mortality by vine apoplexy was the most reliable indicator for assessing the impact of Esca on both production and the condition of the plot. This parameter was therefore used as a reference for the comparison of the impact of Esca with and without the use of the genodic process. Case study la groups the plots for which historical data on Esca-related mortality could be retrieved from vine growers (chefs de culture des vignes) who are in the habit of counting and replacing dead strains every year. With these data, a chronology of the mortality rate before and after the implementation of the genodic process was carried out, in order to report on the comparative evolution of each plot exposed to the acoustic sequences. The reference value of the mortality rate used in Case $1 \mathrm{~b}$ corresponds to the average of the mortality rates of the previous years, before the genodic process was set up, as evaluated by the vine growers when replacing the dead strains, a task that they carry out every 2 or 3 years. In both cases, an evaluation of Esca-related mortality was carried out at the end of the first year of application of the process, by the Genodics team accompanied by the vine grower, and was repeated in subsequent years.

Case 1c: Prevention and reduction of the impact of Esca on the vine, with a control plot.

Study carried out at the Château Gaudrelle in Vouvray, from 2014 to 2019, on two plots about $500 \mathrm{~m}$ apart, planted in the same year (1986) with the same grape variety and in the same terroir. The counting of vines showing symptoms of Esca has been carried out every year since the genodic process was implemented, and systematically validated with the vine grower, on the same day for both plots $(3,972$ individual plant locations for the control plot and 6,050 locations for the tested plot).

Case 2: Prevention and reduction of the impact of Mildew on a 7-ha vineyard.

At the Château Fayau in Cadillac, in 2016, a 7-ha vineyard received the usual anti-mildew fungicidal treatment applied by the vine grower. The diffuser was placed at one end of the vineyard, and diffusions were perceptible up to $150 \mathrm{~m}$ from this spot. Eighty-five plots comprising five vines each were selected, regularly spaced to cover the entire vineyard. At the beginning of July 2016, the number of mildew blotches on grapes (visible mark of the disease) on each plot was recorded.

Case 3: Prevention and reduction of the impact of Erwinia on endives.

Study carried out at the market garden Delahaye in Touraine, during the growing season 2011-2012 from mid-October 2011 to the end of March 2012. This experiment was carried out 
during the endives' forcing phase, inside a thermo-regulated room with ambient humidity saturation. For each batch of endives, placed in containers, the cultivation period (forcing) lasted about 20 days, during which time the roots were permanently bathed in a nutrient solution. On maturity, the containers were removed from the forcing room and the endives harvested. New containers were immediately put in place for the next crop. During the 25 weeks of the season, acoustic diffusions were made for periods of 21 days, followed by 21 days without diffusion, alternating. Thus, depending on their date of entry into the forcing room, the endives in each container received between 1 and 20 days of these sound broadcasts, during which the sequences were broadcast daily for 24 minutes at the beginning of season and 34 minutes at the end of season.

In this way, a diffusion gradient over time was realised in order to compare the batches, with some receiving 500+ minutes at the beginning of the season and others $700+$ minutes at the end. The loudspeakers of the diffusion system were installed inside the thermo-regulated room, while the amplifier and programmer were placed outside the room. For each batch, in addition to its exit date from the forcing room (i.e. the date of harvest), the following characteristics were recorded:

- Quantity of endive produced, in kilograms;

- Duration of the broadcast on the batch, from 0 to the total number of days spent in the room (up to 21 days);

- Percentage of 'second-grade' endive (based on the exterior appearance such as shape, size and quality) in relation to the total produced;

- Production yield, in number of endives and in kilograms per container (based on kg per container $\times$ no. containers per batch).

A total of 541 tonnes of endives produced under these conditions, grouped by batch, were analysed.

Case 4: Reduction of the impact of Mosaic Virus on courgettes.

This experiment was carried out on the market garden of l'Oustalet, Bouches-du-Rhône, in 2009, in 7 polytunnels on a sample of 100 courgette plants per tunnel (over $400 \mathrm{ft}$ of plants in total, of the Satellite variety). The tunnels were $7 \mathrm{~m}$ wide, $80 \mathrm{~m}$ long and $3 \mathrm{~m}$ apart. The tunnel closest to the diffusion device was $20 \mathrm{~m}$ from the device, and the furthest tunnel was between 87 and $94 \mathrm{~m}$ from the device. The tunnels were installed perpendicular to the direction of the Mistral wind, and the sound was emitted in the opposite direction to the Mistral. The sequences, aimed at reducing the proliferation of viruses and stimulating the resistance of the courgettes, were broadcast once a day for 6 minutes throughout the production phase from 30 July (planted on 6 July, first harvest on 6 August). For each selected courgette plant in each tunnel, the following criteria were recorded:

- healthy plants;

- plants showing virus-related symptoms (filiform or mottled leaves);

- dead plants.

In this way, the degree of impact of the virus could be assessed in a gradient from the loudspeaker to the furthest tunnels.

\section{RESULTS}

Case 1a: Prevention and reduction of the effects of Esca on the vine, with historical data.

The historical values of the Esca mortality rate are plotted in Figure 10.1a and b, together with mortality rates collected year by year from the start of the genodic process (year 1). Prior to year 1, the mortality rate averaged between $1.8 \%$ and $5.5 \%$. From year 1 onwards, there is a progressive decrease in the mortality rate, around $1.5 \%$ in year 1 (start of the diffusion process) and then between $1 \%$ and $2 \%$ mortality in the following years. The difference between before and after 


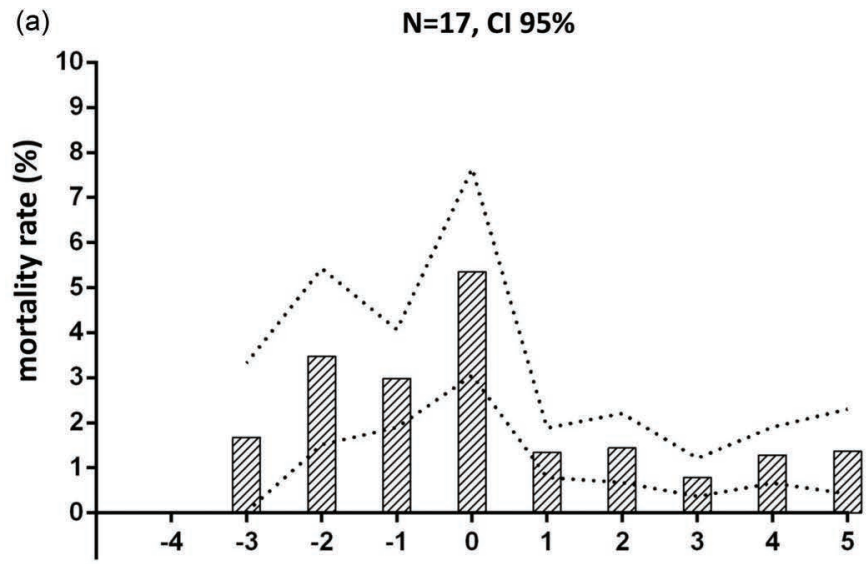

(b)

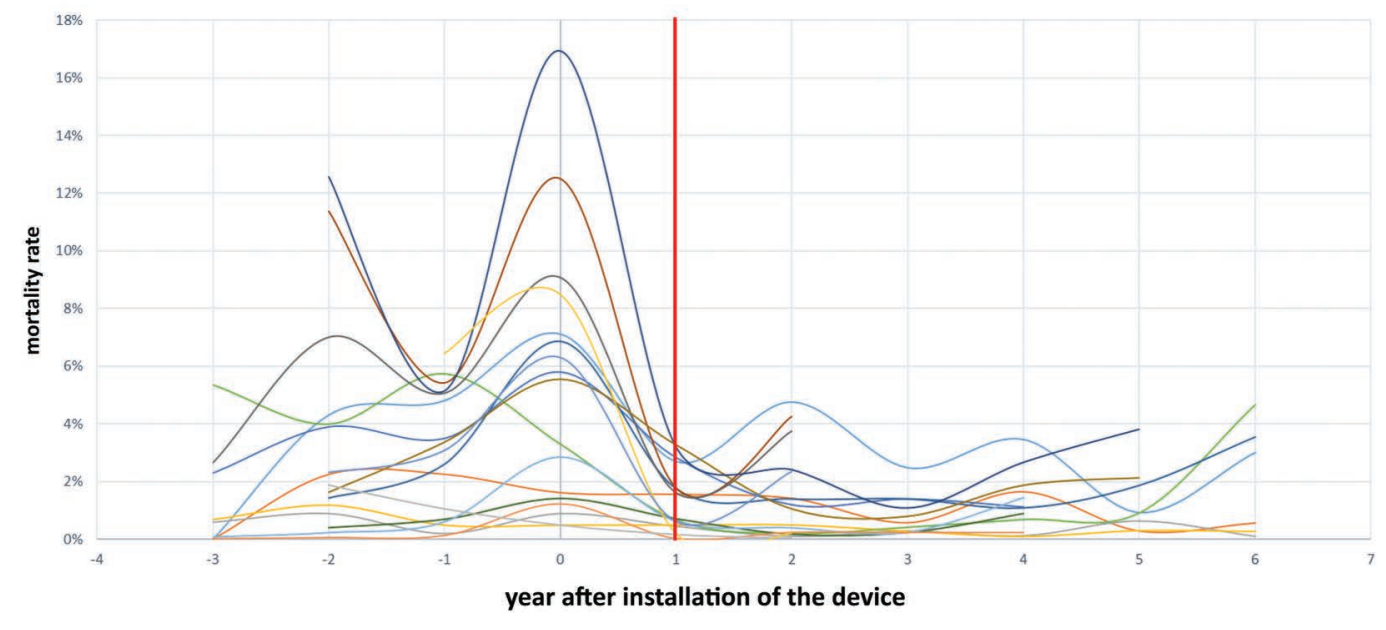

FIGURE 10.1 (a) Evolution of Esca-related mortality rate before and after genodic use. (b) Esca-related mortality rate before and after genodic use.

implementation of the process is significant with a $95 \%$ confidence interval. These results cover data from 17 plots, for a total area of 43 ha (about 200,000 vine stocks).

Case 1b: Prevention and reduction of the impact of Esca on vines, with historical averages.

Mortality data related to Esca collected year after year were used to calculate the evolution of this mortality based on the historical average of each plot. The historical average was the percentage loss per year before the beginning of the experiment, based on 3-5 years of available data. The colour curves in Figure 10.2 show the evolution of mortality rates on the 91 plots, each compared with the local average mortality rate; the black line shows the annual means; and the vertical bars show the confidence intervals for each year's data, with a chosen confidence index (CI) of 99\%. There is an average decrease in the mortality rate of $57 \%$ from the first year of use, then a stabilisation in the following years to between $50 \%$ and $65 \%$ of the initial mortality rate. The yearly variations are mainly related to differences of climatic conditions in the areas of these plots.

Figure 10.2 also shows the raw data used to calculate the average data, represented by the curve described above. It is interesting to note that the variations in the mortality rate have a large amplitude depending on the plots. The dispersion of these results reflects a statistical effect of the process, spread over all the treated plots, with a central value of between $50 \%$ and $70 \%$ reduction in Esca-related mortality. 


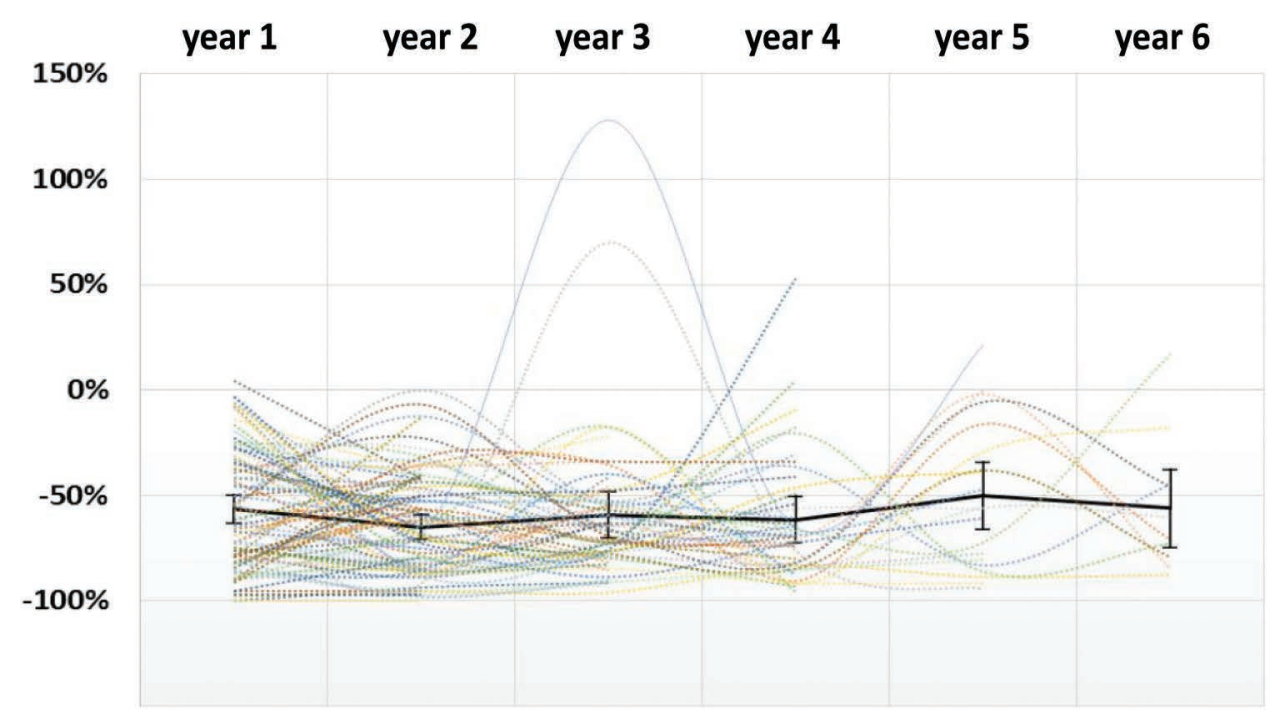

FIGURE 10.2 Evolution of the Esca mortality rate compared to the average historical mortality rate ( $N=91$ plots), 1,209,020 vine stocks on 260 ha total, CI 99\%.

Case 1c: Prevention and treatment of Esca on vine, with control plot.

By comparing the results obtained for the control plot and the genodic plot, it can be noted that for both symptoms and mortality rate, Esca expression varies in the same way depending on the year on both plots. This corroborates the similarity of the plots and the context in which they evolve (climate, pathogens, exposure, etc.). Concerning symptoms such as mortality, a systematically lower rate is observed on the genodic plot that received the acoustic sequences (Figure 10.3a and b). These differences are between $38 \%$ and $80 \%$ less for total Esca expression (symptom + mortality) in the plot that received the sequences (Figure 10.3e). When observing the distribution of results in graphs in Figure 10.3c and d, it appears that the dispersion of values is greater for the control plot, which is more marked for the symptoms (value between $0 \%$ and $4 \%$ for the 'genodic' plot and between $0.5 \%$ and $11 \%$ for the 'control' plot). All these results indicate a difference in the development of Esca on these two plots with otherwise identical characteristics. The annual seasonal patterns that condition the natural development of the Esca are well distributed from plot to plot each year, but appear to be markedly reduced, between $38 \%$ and $80 \%$, in the plot that was exposed to the genodic sequences.

Case 2: Prevention and reduction of the impact of Mildew on a 7-ha vineyard.

The number of blotches on bunches of grapes relating to the presence of mildew was counted by plots of five vines ( $n=83$ plots). These values were represented according to the distance of each group from the scattering device. Figure 10.4 shows an increase in the number of mildew blotches as a function of distance, particularly at distances of $150-200 \mathrm{~m}$. The linear regression of the data on the graph (curving upwards) shows a strong decrease at this distance, which corresponds to the acoustic diffusion range limit of the installed equipment. Between 0 and $150 \mathrm{~m}$, the number of blotches by plot ranges from 0 to 1 , and then, it varies from 1 to 7 blotches by plot between 150 and $250 \mathrm{~m}$. The correlation between proximity to the device and the number of blotches is represented by the linear regression curve, within the $99 \%$ confidence interval shown as a dotted line on the graph. These results show an increase in the impact of mildew on grape clusters as one moves away from the genodic sequence diffuser, with a noticeable increase more than $150 \mathrm{~m}$ from the diffuser.

Case 3: Prevention and reduction of the impact of Erwinia on endives.

Batches of endives were grouped according to the duration of their stay in the forcing chamber. Figure 10.5a shows the change in the percentage of second-grade endives as a function of the duration of exposure, showing a clear decrease in the rate of second-grade endives with increasing exposure 
(a) Esca symptoms evolution 2014-2019

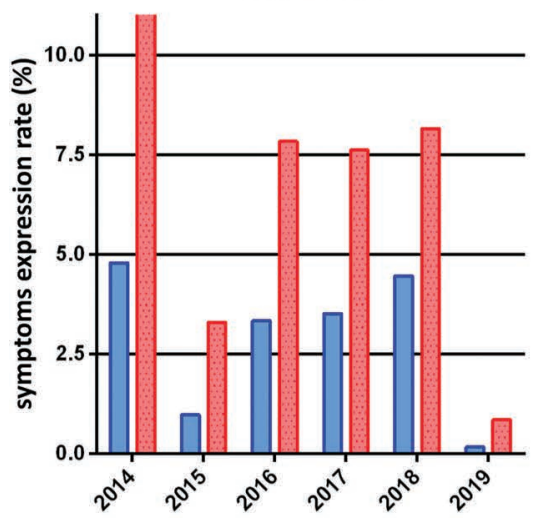

(c) Synthesis of symptoms expression

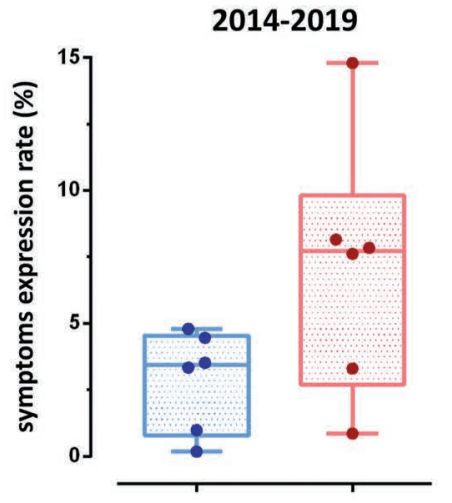

(b) Esca-related mortality evolution

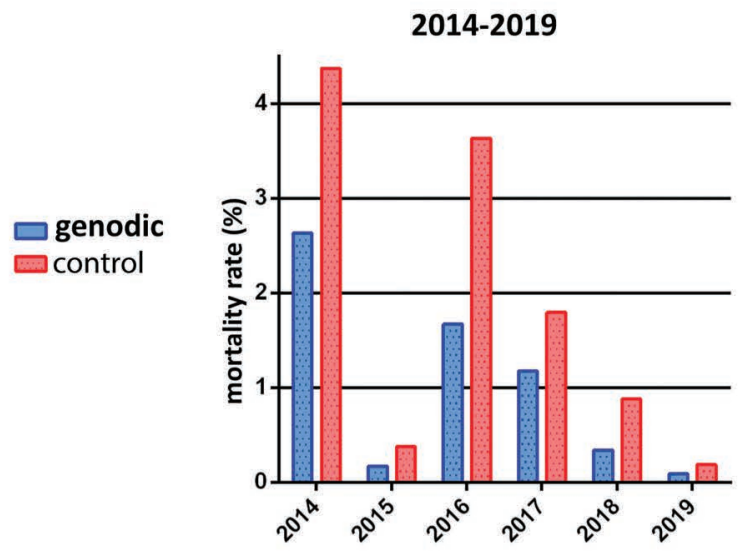

(e)

Esca symptoms comparison

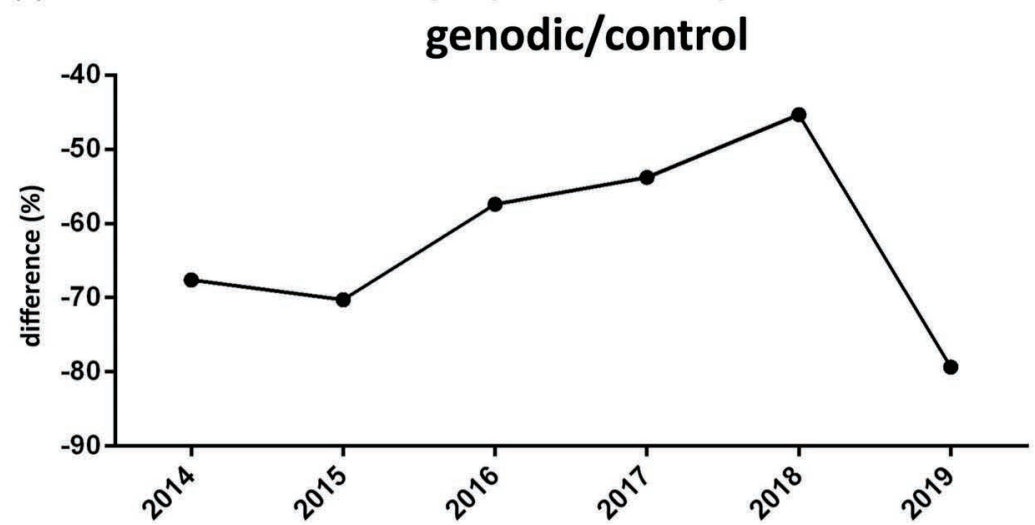

FIGURE 10.3 (a-e) Comparison of the evolution of Esca with and without genodic treatment. 


\section{Number of mildew blotches by plots of 5 vines as a function of the distance from the device $\mathrm{Cl} 99 \%-\mathrm{N}=83$ plots/415 vines}

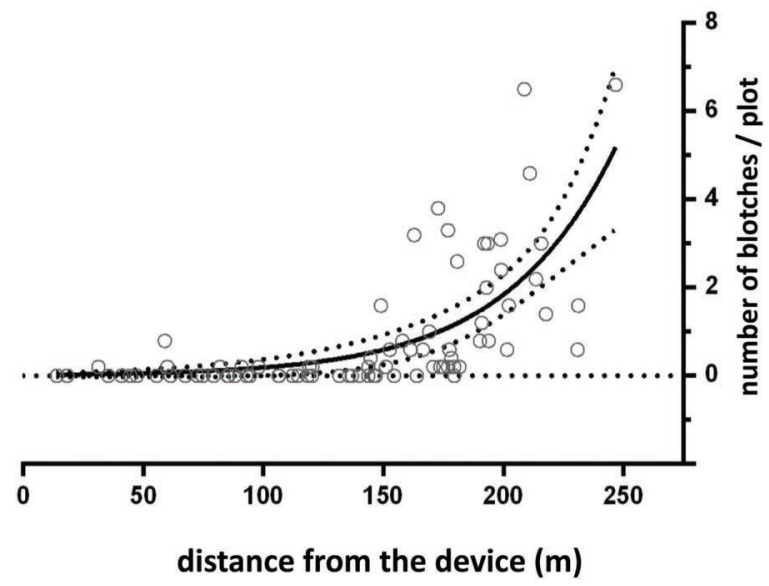

FIGURE 10.4 Number of mildew blotches on grapes, on each plot of five vines, as a function of the distance from the broadcasting device.

(a) $\mathrm{Cl} 95 \%-\mathrm{N}=\mathbf{2 1 1}$ series/541 $\mathrm{t}$ of endives

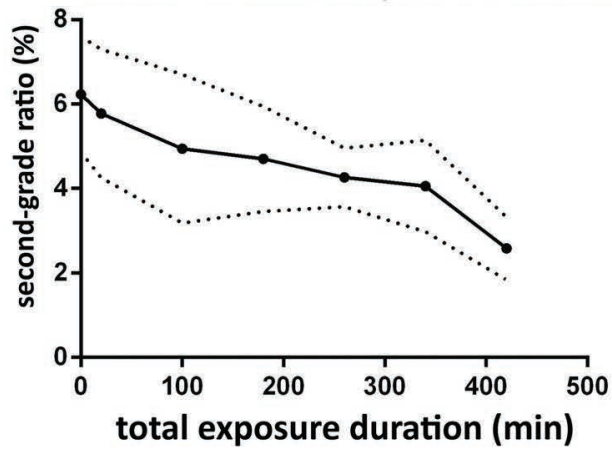

Linear regression of the curve

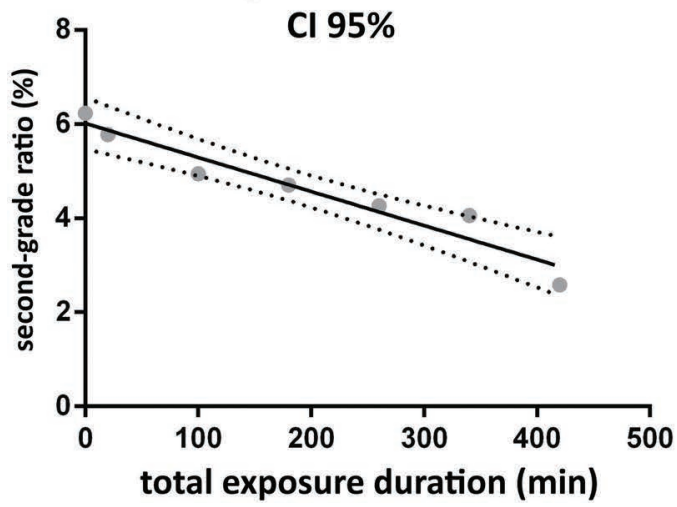

(b) $\mathrm{Cl} 95 \%-\mathrm{N}=\mathbf{2 1 1}$ series/541 $\mathrm{t}$ of endives

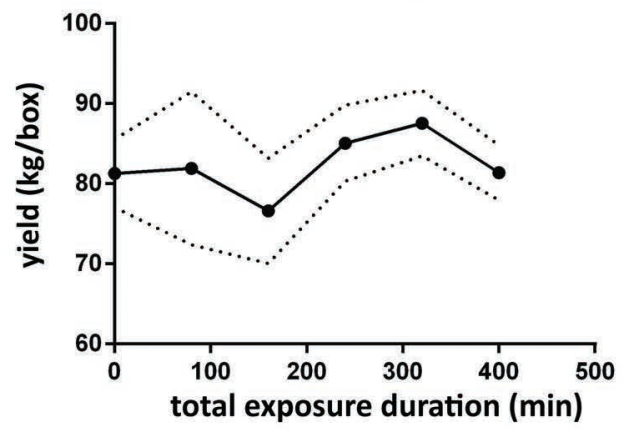

total exposure duration ( $\mathrm{min})$

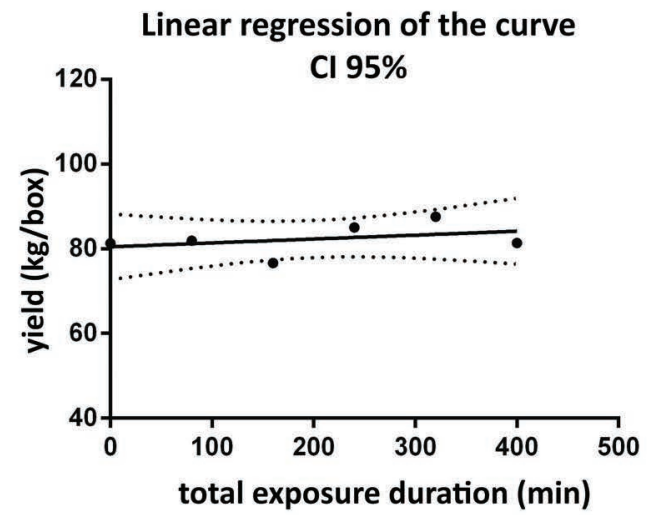

FIGURE 10.5 (a) Change in percentage of second-grade endives as a function of duration of exposure. (b) Evolution of endive yield as a function of exposure time. 
to the genodic sequences. Batches that received no diffusion had a rate of second grade of around $6 \%( \pm 1.5 \%)$; then, this rate decreases with diffusion time until it reaches the minimum value around of $2.5 \%( \pm 0.5 \%)$ for a maximum diffusion time of 400 minutes spread over the duration of the forcing (20 minutes each day). The linear regression of these points shows a reduction by a factor of 2 , between no diffusion (6\%) and 400 minutes of diffusion (3\%). In Figure 10.5b, there is an insignificant increase in performance as a function of the duration of exposure to the sequences. The high variability for the production of each batch results in a large confidence interval (between \pm 5 and $\pm 10 \mathrm{~kg} /$ container, although a (insignificant) trend towards increased yield can be observed by linear regression of the data.

Case 4: Reduction of the impact of Mosaic Virus on courgettes.

(Actual distances from the tunnels on the device are as follows: 20, 30, .., $80 \mathrm{~m}$.)

In each tunnel, the values for the number of healthy, diseased or dead plants (as a result of Mosaic Virus) were plotted as a function of the distance from the tunnel to the sequence delivery device. The number of diseased plants increased sharply $30 \mathrm{~m}$ away from the diffusion apparatus (tunnel number 3), and then increased more gradually up to plants between 80 and $100 \mathrm{~m}$. The number of symptomatic plants at $30 \mathrm{~m}$ appears to be an exception in the linear progression of the number of unhealthy plants, as observed in the linear regression of values (Figure 10.6). The number of healthy
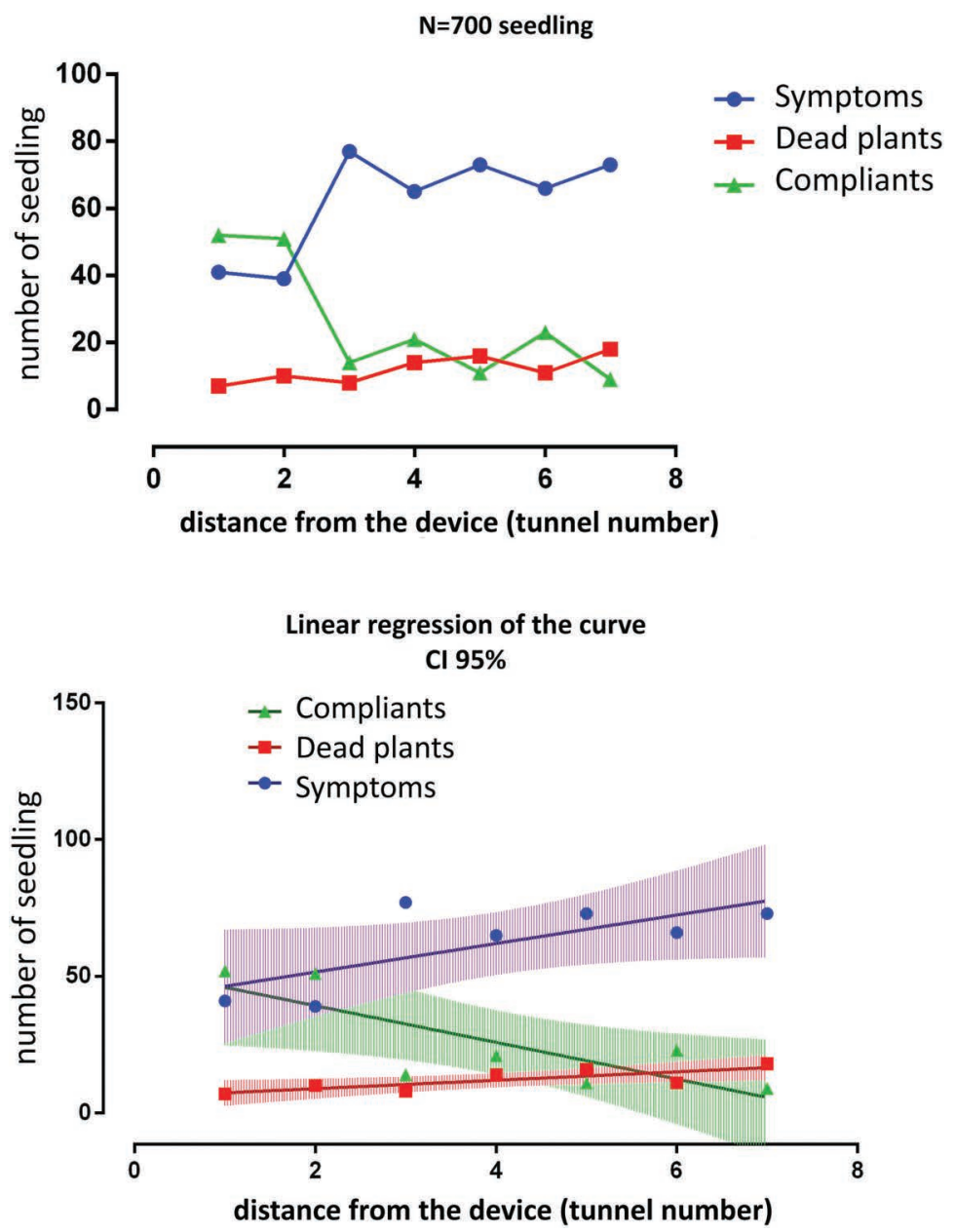

FIGURE 10.6 Virus expression as a function of distance from the delivery device (where compliant signifies healthy). 
plants follows the same progression in reverse, decreasing with the distance from the scattering device, from $50 \%$ at $20 \mathrm{~m}$ to $0 \%$ at $80 \mathrm{~m}$. Mortality increased linearly with distance, from $5 \%$ at $20 \mathrm{~m}$ to $20 \%$ at $80 \mathrm{~m}$. The most reliable parameter here is the evolution of mortality, which had a narrower confidence interval and showed a more significant trend. However, the tendency for symptoms to decrease with distance from the device is clearly identifiable, particularly through linear regression of the data.

\section{CONCLUSION}

Through these case studies, we have observed the effects of the diffusion of the sound sequences designed by Genodics on plant production results as the following:

- a significant decrease in mortality linked to the vine fungus Esca (between 50\% and 70\%);

- a reduction in the proliferation of Mildew on grapes by a factor of 6 ;

- a reduction in virulence in the case of Mosaics on courgettes;

- a significant reduction in the number of second-grade endives, by a factor of 2 , through the prevention of Erwinia.

Our experiments demonstrated that within a certain range, the effect of proteodies on plants is proportional to the duration of the broadcast and the power of the sound. This second factor diminishes with the distance from the loudspeaker, resulting in an effect gradient which can be measured.

In the case of Mildew on grapes and Mosaic on courgettes, a spatial gradient of the effect of genodic sequences was noted, while in the case of endives, there was a temporal gradient. This corroborates observations made elsewhere in the field with regard to distance from the diffusion apparatus and diffusion duration. The results are consistent with the characterisation of the effects obtained with this process, over a large number of repeated measurements and several models. These results, in addition to those obtained during the validation of Sternheimer's patent, ${ }^{1}$ provide elements that validate the concept developed by Sternheimer and the applications that have followed on since.

This observation is further supported by recent experiments conducted on human cancer cell cultures, published in 2018, during which the assay of the protein specifically targeted by the acoustic sequences was carried out (Orhan \& Gulbahar, 2016). Further, plant culture and target protein assays under the conditions of application of the genodic process have recently been implemented in the ERRMECe laboratory at the University of Cergy-Pontoise, Paris (CERGY, 2017). These results, which largely concur with those of this study, were published in September 2020 (Prevost et al., 2020).

The cases presented here represent only a portion of the applications developed by Genodics. The other applications have not benefited from as exhaustive and precise monitoring as the studies cited here, and some applications did not succeed, either because their results were inadequate to be economically interesting or for reasons independent of Genodics' activity. This study demonstrates the effectiveness of chemical-input-free methods for crop protection and support.

Disclaimer: The information contained in this chapter is the property of Genodics SAS. The implementation of the proteodies is protected by copyright.

\section{ACKNOWLEDGEMENTS}

We would like to thank all those who participated in the development of this work in biology, in particular Marie-Claude Lang, Vincent Bargouin and Michel Cressy, as well as Jacques-Joël Houziel,

\footnotetext{
${ }^{1}$ METHOD FOR THE EPIGENETIC REGULATION OF PROTEIN BIOSYNTHESIS BY SCALE RESONANCE, https://worldwide.espacenet.com/publicationDetails/originalDocument?FT=D\&date=20070829\&DB=EPODOC\&local e=fr_EP\&CC=EP\&NR=0648275B1\&KC=B1 (accessed 23 September 2020).
} 
Jean-Marie Pelt and Christian Loizeau. We would also like to thank the vine growers, market gardeners and arboriculturists who have placed their trust in us and who have contributed to these and other research projects. We would also like to thank all Genodics shareholders and all those who have supported and accompanied the company since its inception.

\section{REFERENCES}

Bargoin, V., Ferrandiz, P. Sternheimer, J. et al., (2004) Application Expérimentale d'un Procédé de Régulation Epigénétique de la Biosynthèse des Protéines au Traitement de 1‘ESCA. Réseau Associatif de Chercheurs Indépendants (RACHI), Paris, France.

CERGY (2017) La Musique Soigne les Plantes: ERRMECe à la recherche de preuves scientifiques. Research News, 30.11.2017. CERGY Paris Université. https://www.u-cergy.fr/fr/recherche-et-valorisation/ actualites-recherche/musique-et-plantes.html.

de Broglie, L. (1924) Recherches sur la théorie des Quanta. Physique [physics]. Migration - université en cours d'affectation, Français. https://tel.archives-ouvertes.fr/tel-00006807/document.

Ferrandiz, P., Duhamel, M., and Sternheimer, J. (2018) Epigenetic Regulation of Protein Biosynthesis by Scale Resonance: Study of the reduction of ESCA effects on vines in field applications - summary 2016. In Life Sciences, Information Sciences (pp. 305-315). https://www.researchgate.net/publication/324266455_ Epigenetic_Regulation_of_Protein_Biosynthesis_by_Scale_Resonance_Study_of_the_Reduction_of_ ESCA_Effects_on_Vines_in_Field_Applications_-_Summary_2016.

Orhan, I. and Gulbahar, B. (2016) Stimulation of protein expression through the harmonic resonance of frequency-specific music. Clinical and Investigative Medicine 39(6): S34-S38.

Prevost, V., David, K., Ferrandiz, P., Gallet, O., and Hindié, M. (2020) Diffusions of sound frequencies designed to target dehydrins induce hydric stress tolerance in Pisum sativum seedings. Heliyon 6(9): e04991

Sternheimer, J. (1992) Procede de Regulation Epigenetique de la Biosynthese des Proteines par Resonance d'Echelle. Patent: EP 0648275 B1. https://www.researchgate.net/publication/279181729_PROCEDE_ DE_REGULATION_EPIGENETIQUE_DE_LA_BIOSYNTHESE_DES_PROTEINES_PAR_ RESONANCE_D'ECHELLE.

Sternheimer, J. (2006) Genodics applied to ecosystem healing. Colloque Serge Winogradsky aujourd'huiAt: SIAAP; Colombes (France). https://www.researchgate.net/publication/269402342_Genodique_appliquee_ a_la_guerison_des_ecosystemes. 